\title{
Patient education in Europe: united differences
}

\author{
Adriaan Visser $^{\mathrm{a}, *}$, Alain Deccache ${ }^{\mathrm{b}}$, Jozien Bensing ${ }^{\mathrm{c}}$ \\ ${ }^{\mathrm{a}}$ Helen Dowling Institute, P.O. Box 85061, 3508 AB Utrecht, The Netherlands \\ ${ }^{\mathrm{b}}$ Department of Health Education and Patient Education, Université Catholique de Louvain, Brussels, Belgium \\ ${ }^{\mathrm{c}}$ NIVEL, Netherlands Institute of Primary Health Care, Utrecht, The Netherlands
}

\begin{abstract}
This issue of Patient Education and Counseling presents the state of the art of patient education in several European countries. It is based on papers presented at a meeting in Paris on the evolution and development of patient education in western, central and eastern Europe (May 1999). Also patient education in the US is presented in this issue. Patient education is defined as all the educational activities directed to patients, including aspects of therapeutic education, health education and clinical health promotion. Five important factors are identified in the development of patient education: (1) research and evidence based standards; (2) the organization of care; (3) training and methodological support; (4) professional values; and (5) acknowledgment, funding and place of patient education in health policy. Several of the discussed common orientations and priorities in the patient education in the reviewed countries are highlighted in this issue. And finally, an example of the possible integrated international practice in patient education in the field of diabetes is described in this issue. Several conclusions are drawn concerning future development of communication in health care within the framework of patient education in Europe. (C) 2001 Elsevier Science Ireland Ltd. All rights reserved.
\end{abstract}

Keywords: Patient education; Europe; Diabetes; United States of America; Communication; Health care; Health policy

\section{Introduction}

Europe is a growing united political and social system. Health care is a central part of the EC policy. There are open boarders for health care consumers. However, patients may be confronted with differences in standards for the quality of care. Patient education is one of the areas that might be affected. Insight in existing differences in patient education may contribute to the development of international accepted norms for communication in health care.

In May 1999, a European meeting was held in Paris on the evolution and development of patient education

\footnotetext{
* Corresponding author. Tel.: +31-3-252-4020; fax: +31-3-252-4022.

E-mail address: adriaan.visser@wxs.nl (A. Visser).
}

[1]. The initiative was partly supported by the French government in order to integrate experiences with patient education in other countries in the French health care reform plans. Several of the discussed common orientations and priorities are highlighted in this issue. Although different definitions of patient education are often used, the following working definition was agreed as during the conference: "Patient education concerns all educational activities directed to patients, including aspects of therapeutic education, health education and clinical health promotion" [2].

In this issue of Patient Education and Counseling, the state of art of patient education in several European countries is presented. The results of the Paris meeting are presented in a separate article [2]. In an article, special written for this issue, the development of patient education in the US is also analyzed [3]. To 
conclude, an international perspective on patient education in the field of diabetes is presented in this issue [4].

\section{Western Europe}

The history and development of patient education in eight western European countries is presented in this issue: Belgium, Finland, France, Germany, Italy, The Netherlands, Switzerland, and the UK. In each country those aspects are highlighted that are relevant for the development of patient education in that particular. As a result, the analysis of the patient education in the eight countries stresses different aspects of patient education in every country [2], showing the development of patient education in all its diversity.

Patient education not only covers the general health education for potential users of health care, but also patients' rights and ethical issues in the field of patient education. These general features of patient education are strongly present in the contributions of patient education in the UK [5], Belgium [6], Germany [7] and The Netherlands [8]. In various countries, patient education struggled for recognition in the health care system, like in the UK [5], Italy [9], and Finland [10], while for other countries the national governmental support was important, e.g. The Netherlands [8] and Belgium [6].

In a lot of countries, general practitioners play a central role in patient education. The GP is the key person within primary health care and the gatekeeper of the health care system The prominent role of primary health care and the GP in patient education is clearly present in the contributions of nearly all countries [5-13].

Traditionally, in several countries also hospitals played a relevant role in the development of patient education. Hospitals researchers showed the benefits of patient education for shortening the length of stay, lowering the anxiety of the patients, increasing patient satisfaction and improving effectiveness of health care [14]. This part of patient education is presented in the analysis of patient education in the Belgium [6], The Netherlands [8], and France [12].

Patient education for people with a chronic disease gets a growing attention [15]. Especially the education for diabetes patients is a well developed area. The articles on patient education in Italy [9], Sweden [13] and Switzerland [11] highlight the importance of patient education for this group of patients. In addition, in various countries the important role of patient education in chronic diseases is recognized and practiced, like Sweden [13], The Netherlands [8], Germany [7], Italy [9] and the UK [5].

Counseling is often still a neglected aspect of patient education, although therapeutic aspects of patient education is more and more recognized, stressing all educational activities essential to the management of diseases, for patients as well as their families, trying to improve their quality of life [16]. Especially in the contributions about Switzerland [9] and Italy [11], the impact of therapeutic patient education is stressed.

The communication in health care and the training of health care providers in patient education plays a central role in the development of effective patient education [17]. In fact in all the contributions about patient education in the European countries the necessity of training in communication skills as well as its profits are recognized. In a few articles the importance of interdisciplinary cooperation in patient education is stressed, e.g. Belgium [6], France [12], The Netherlands [8], while these contributions also underline the role of nurses in patient education.

In their review of the Paris meeting, Deccache and Aujoulat [2] describe that the improvement of patient education in European countries is influenced by five important factors: (1) research and evidence based standards; (2) the organization of care; (3) training and methodological support; (4) professional values; and (5) acknowledgment, funding and place of patient education in health policy. The papers about the history of patient education in western Europe show that patient education is mainly determined by the characteristics of the health care system. Van den Brink-Muinen et al. [18] indicated that patients' view on doctor-patient communication in different European countries is strongly influenced by the gatekeeping role of the GP. This study especially shows that patients in non-gatekeeping countries considered both biomedical and psychosocial communication aspects to be more important than the patients in the gatekeeping countries. Patients also report that non-gatekeeping GPs deal more often with these aspects. 
So it seems that not only traditionally national and cultural differences define the history of patient education, but that also the principles of the health care system as such influence the progression of patient education. The policy of a United Europe may change the national health care systems. The future consequences of this policy for patient education requires more study and research.

\section{Central and eastern Europe}

Until the end of the 1980s, the countries of central and eastern Europe could be characterized by uniformity in the provision of health care services. Based on a survey among GPs in 12 eastern and central European countries, Grielen et al. [19] conclude that at the moment there is no more uniformity in the profile of the GP in these countries then in western European countries. In eastern Europe there are in fact considerable differences. GPs in former Yugoslavia have the most comprehensive service profile, where the lowest scores were found among doctors from the former Soviet Union. Those countries that had a social insurance system before the second world war, such as the Czech republic and Hungary, are situated in between. The authors conclude that there are distinctive national differences in GPs' task profiles in central and eastern Europe, which provide clues for the country-specific design and implementation in primary-care oriented reforms. Although Grielen et al. [19] do not stress the consequences for patient education, the necessary changes in primary health will imply consequences for patient education by GPs, as the development of patient education in western European countries showed [2,5-13].

The still evolving health care system in eastern Europe is one of the reasons that it is difficult to present a stable picture of the features of patient education in these countries. A description of patient education within the existing framework of the paternalistic role of the physician would not apply within the next decade. But also the implications of the ongoing health care reforms for patient education will yet not be clear in these countries. This may explain why in eastern and central European countries the ideal situation is often more stressed rather than the actual situation. It is, therefore, important that countries of eastern and central Europe participate in projects of the western European countries, like projects on health promoting hospitals, or the activities of European organizations in the field of diabetes, cancer, health, and communication in health care [4,17,20-22].

In the contribution about Hungary [23] and Estonia [24], several good examples are presented to what impact changes in the health care system may have on patient education. For Hungary the historical roots of patient education in the 19 th century are clarified, a tendency also described by Roter [3]. In Hungary as well as in Estonia the role of patient education in the primary health care and the interdisciplinary cooperation is highlighted.

\section{The United States as mirror}

Patient education in one country may function as a mirror for the quality of patient education in other countries. This mirror for Europe is presented in a special contribution about patient education in the US. Roter [3] stresses that patient education in the US has transformed and reinvented itself many times since the germination of its roots in early medical, nursing, and public health practice. In tracing these historical roots, Roter cites Bartlett [25], who identifies the formative period of patient education as beginning in the mid1800s and shaped by a mix of societal forces that included changes in the supply and demand of physicians, new roles for community and allied health professionals, emerging medical technologies, and the changing nature of the patient-physician relationship. Many of these same societal forces are in play today challenging the profession to once again transform itself. As in Europe, in the decade of the 1960s dynamic changes was once again evident in patient education [8]. Developments in the civil rights movement, the women's movement, and the growing consumer and self-help movements converged in their pressure for greater social equity and empowerment of both patients and communities. These themes were reflected in the ground-breaking Ottawa Charter and writings of influential academic leaders in the field throughout the 1980s and 1990s. Consistent with these influences, the Society for Public Health Education has defined a common set of competencies and a 
philosophy for the field that values and promotes patient participation and empowerment at an individual, organizational, and community level. The purpose of Roter's essay is to reflect on both the historical and contemporary context of health education in the US, to recognize the challenges of changing times, and to consider future directions.

\section{Integrated patient education in Europe}

This issue contains an important example of an international perspective on patient education in the field of diabetes. Maldonato et al. [4] present the activities of the Diabetes Education Study Group (DESG), a section of the European Association for the Study of Diabetes, founded in 1979 upon the initiative of Jean-Philippe Assal. The aim of the DESG is described as "to improve the quality of life of the diabetic patient through the development and evaluation of educational programs designed to foster independence for the patient, to improve the quality of metabolic control, to emphasize the importance of prevention and early recognition of the disease and to encourage relevant research". Given the therapeutic role of patient education, doctors must be involved in the entire process, as members of the multi-professional team who carry the responsibility for the planning and implementation of the educational process. Based on these assumptions, the activities of the DESG concentrated on workshops, congresses, teaching letters, a 5 min education kit, a website, and a basic curriculum in therapeutic patient education. These activities have been presented at the national level throughout several national diabetes organizations. The written documents produced by the DESG have been translated into more than 20 languages and distributed all over the world, recently also by their Website on the Internet.

\section{The future}

In several articles in this issue on patient education in Europe, the differences between these countries are articulated. One of the challenges for the near future is to explore these differences in an attempt 'to keep the best of these different worlds'. Especially the influence of health care characteristics (including remuneration systems, distribution of responsibilities, patient rights and so on) on patient education is a very promising area for international research [26].

More in general researchers from different countries should work together to improve the evidence base of patient education [27]. Probably, it would be helpful to view patient education as a specific form of health care communication and join forces with the growing group of communication researchers and teachers of communication skills [28]. They recently started a European Association for Communication in Health Care (EACH). A collaboration between these groups of researchers and teachers would probably be a benefit to both. ${ }^{1}$

A completely different topic is the impact of the digital revolution on patient education, including the role of new media like Internet. Health care issues are very popular at the Internet. Health-related websites are (together with websites on sex and money) the most visited sites. This immense popularity provides new threats (for instance, with regard to the quality and objectivity of the presented information, given the vested economical interests of the producers of this information), but also new challenges, for instance, for interactive, tailor-made patient education. Studies on computer tailored patient education about, e.g. smoking cessation have shown the value of tailored personalized patient education [30].

Patient education has had its ups and downs throughout the years in the different European countries $[2,26,29]$. Combining forces by more international collaboration will not only diminish the differences between the European countries, but can also contribute to a more central role for patient education in health care. Certainly, the attendants at the Paris meeting [2] strongly believed that this would benefit European people in all countries present at the Paris meeting. In a future meeting in Paris, the further development of patient education in the frame work of health education will be presented. ${ }^{2}$

\footnotetext{
${ }^{1}$ For more information about EACH, contact Dr. Sandra van Dulmen at: NIVEL, P.O. Box 1568, 3500 BN Utrecht, The Netherlands. Fax: 31-3-2729729 (e-mail address: nivel@nivel.nl).

${ }^{2}$ Proceedings of the XVIIth World Conference on Health Promotion and Health Education, 2001 July 15-20; Paris (information at www.europa-organisation.com).
} 


\section{References}

[1] Proceedings of the European Seminar on the Development of Patient Education: Policy and Practice, 1999 May 14-15; Paris. Abstract book.

[2] Deccache A, Aujoulat A. An European perspective: common developments, differences and challenges in patient education. Patient Educ Couns 2001;44:7-14.

[3] Roter DL, Margalit R, Rudd R. Currents perspectives on patient education in the US. Patient Educ Couns 2001;44: 79-86.

[4] Maldonato A, Segal P, Golay A. The diabetes study group and its activities to improve the education of people with diabetes in Europe. Patient Educ Couns 2001;44:87-94.

[5] Skelton A. Evolution not revolution? The struggle for the recognition and development of patient education in the UK. Patient Educ Couns 2001;44:23-7.

[6] Deccache A, van Ballekom K. Patient education in Belgium: evolution, policy and perspectives. Patient Educ Couns 2001;44:43-8.

[7] Keller S, Basler H-D. Implications of structural deficits for patient education in Germany. Patient Educ Couns 2001;44:35-41.

[8] Bensing J, Visser A, Saan H. Patient education in the Netherlands. Patient Educ Couns 2001;44:15-22.

[9] Marcolongo R, Rossato E, Pavan V, Laveder F, Bonadiman L, Rigoli AM. Current perspectives of therapeutic patient education in Italy. Patient Educ Couns 2001;44:59-63.

[10] Ojanlatva A. Patient education in Finland. Patient Educ Couns 2001;44:49-54.

[11] Assal J-P, Golay A. Patient education in Switzerland: from diabetes to chronic diseases. Patient Educ Couns 2001;44:65-9.

[12] Fournier C, Mischlich D, d' Ivernois J-F, Sandrin-Berthon B, Menard J. Towards promotion, structuring, an acknowledgment of patient education in France. Patient Educ Couns 2001;44:29-34.

[13] Rosenqvist U. Patient education: new trends in Sweden. Patient Educ Couns 2001;44:55-8.

[14] Devine EC. Effects of psychoeducational care for adult surgical patients: a meta-analysis of 191 studies. Patient Educ Couns 1992;19:129-42.

[15] Visser A. Chronic diseases, aging, and dementia: implications for patient education and counseling. Patient Educ Couns 2000;39:293-309.

[16] World Health Organization. The therapeutic patient education: continuing education programmes for health care providers in the field of prevention of chronic diseases. Copenhagen (Denmark): WHO, 1998.

[17] Bensing JM, Verhaak PFM, van Dulmen AM, Visser AP, editors. Communication: the royal pathway to patient centred medicine. Patient Educ Couns 2000;39: $1-145$.

[18] Van den Briuk-Muinen A, Verhaak PFM, Bensing JM, Bahrs O, Deveugle M, Gask L, Leiva F, Mead N, Messeri V, Oppizzi L, Peltenburg M, Perez A. Doctor-patient communication in different European health care systems: relevance and performance from patients' perspective. Patient Educ Couns 2000;39:115-27.

[19] Grielen SJ, Wieneke GWB, Peter PG. Unity or diversity: task profiles of general practitioners in central and eastern Europe. Eur J Public Health 2000;10:249-54.

[20] Fowler G, editor. Proven strategies for smoking cessation: adopting a global approach. Eur $\mathbf{J}$ Public Health 2000;10(Suppl 3):1-29.

[21] Mckee M, Berman P, editors. Targets for health: shifting debate. Eur J Public Health 2000;10(Suppl 4):1-56.

[22] Towards the harmonisation of health care rights for European citizens. Summary of the preliminary programme. In: Proceedings of the 2nd European Health Care Forum, 2000 May 23-26; Barcelona, Spain.

[23] Trinn Cs, Molnar P. Patient education in Hungary. Patient Educ Couns 2001;44:71-4.

[24] Härm T. Patient education in Estonia. Patient Educ Couns 2001;44:75-8.

[25] Bartlett EE. Historical glimpses of patient education in the United States. Patient Educ Couns 1986;10:135-49.

[26] Assal JPH, Golay A, Visser AP, editors. New trends in patient education: a trans-cultural and inter-disease approach. Amsterdam: Elsevier, 1995.

[27] Bensing J. Bridging the gap: the separate worlds of evidencebased medicine and patient-centered medicine. Patient Educ Couns 2000;39:17-25.

[28] Bensing JM, Verhaak PFM, van Dulmen AM, Visser AP, editors. Communication in health care. Special issue. Patient Educ Couns 2000;39:1-3.

[29] Boske M. Coordination en éducation du patient, experiences Europeennes, perspectives francaises (Coordination of patient education: European experiences and French perspectives). Université Paris Nord. U.F.R. Santé, medicine, Biologie Humaine Leonard de Vinci. Department de Pédagogie des Sciences de la Santé, Paris, 2000.

[30] Brug J, De Vries H. Computer-tailored education [special issue]. Patient Educ Couns 1999;36:99-205. 